\title{
Occlusal, joint and muscle condition of a young adult population
}

\author{
Abstract \\ Introduction: The normal function of the stomatognathic ystem (SMS) depends on \\ the harmony of close relationship among temporomandibular joint (TMA), occlusion \\ and neuromuscular system. This study described this SMS characteristics of young \\ adult people.
}

Methods: Descriptive study, intention sample of 60 patients with complete natural dentition that observed the main occlusal characteristics, TMA and temporal and masseter muscles, through, clinical examination, mounting semi-adjustable articulator and surface electromyography.

Results: Patients recorded: ATM noise (43\%), limited opening (13\%), normalocclusion in static position $(56-71 \%)$, premature contacts $(20 \%)$ interferences $(93 \%)$ and opening deviation (51 \%). In patients with occlusal alterations there was an increase in muscle electrical activity (right masseter $\mathrm{p}<0.05$ ).

Conclusion: Clinical and occlusal conditions that did not coincide with normalocclusion parameters generated an increase in muscle electrical activity.
Volume 4 Issue 4 - 2019

\author{
Oscar Hernán Zuluaga-Lopez,' Olga Patricia \\ López-Soto ${ }^{2}$ \\ 'Dentist, Oral Rehabilitator, professor of postgraduate ora \\ rehabilitation program, Autonoma University of Manizales, \\ Columbia \\ ${ }^{2}$ Dentist, Master in Clinical Epidemiology, professor of \\ postgraduate oral rehabilitation program, Autonoma University \\ of Manizales, Columbia
}

\begin{abstract}
Correspondence: Olga Patricia Lopez Soto, Dentist, Ora Rehabilitator, professor of postgraduate oral rehabilitation program, Autonoma University of Manizales, Columbia, Tel (57+068)8727272 ext 162, Email sonrie@autonoma.edu.co
\end{abstract}

Received: July 06, 2019 | Published: July II, 2019

Keywords: dental occlusion, young adult, temporomandibular joint

\section{Introduction}

Dentistry today has been using various and multiple technological advances related to dental materials, restorative and new theories that revolutionize traditional conceptions. Those techniques are being more applied to treatment of patients with different needs.

Occlusion, as other areas of dentistry, has its theoretical conception, which becomes a point of reference for specialties of dentistry. ${ }^{1}$ However, this entire theoretical concept has been built on classical parameters of different occlusal schools that underlie clinical criteria of treatment options for the clinical condition of the patients.

Those classical parameters of the theoretical foundations have been built at a specific time and with certain ethnic groups that have become normality standards. Nowadays, occlusion is classified as "ideal and normal", which causes semantic misunderstandings because "ideal" is used in a hypothetical concept, whereas "normal" involves variations on average on clinical differences. This implies that there should not be ideal occlusion because it demands unchanged inheritance, excellent conditions and a history development without any accident, disease or event that could change both growth pattern and ideal conditions of the human being. ${ }^{2}$

Currently, the concept of occlusion is broader than that of dental interdigitation and it should include functional, parafunctional and dysfunctional relationships that arise from the contact of occlusal surfaces of teeth during different phases of the masticatory cycle ${ }^{3}$ and its close relationship with mandibular and joint dynamics of both temporomandibular joints, considering that the energetic and coordinated contraction of different jaw muscles are in the middle. ${ }^{4}$

The normal function of the stomatognathic system depends on the harmony of all components due to the close relationship among temporomandibular joints, occlusion, neuromuscular system, even with the rest of the body. ${ }^{5}$ Since, specific effects of occlusal interferences on temporomandibular joint have been controversial, it is also clear that, given the close functional relationship between teeth and TMJ, the occlusal unbalance may be a factor to dysfunction of masticatory system. ${ }^{6}$ In contrast, occlusion has been considered an etiological factor to develop temporomandibular disorders, although there is not clear scientific evidence to support a significant strong relationship between malocclusion and different joint diseases. ${ }^{7}$

Despite the controversy about the relation between joint pathological signs and occlusal conditions, the description of normal concepts include Angle static occlusal relationships with various modifications as Andrews keys of occlusion, ${ }^{8,9}$ articulated with specific non-occlusive patterns as canine guide, previous guide and mutually protected occlusion. ${ }^{10}$ However, research currently shows that occlusal harmony is not the only requirement, it also demands the health and physiology of the neuromuscular system to coordinate mandibular and articular dynamics. ${ }^{11}$

Electromyography has been an increasingly important point in studying changes in masticatory neuromusculature and it provides clinical data about the anatomy and physiology of the skeletal muscle during voluntary contractions. There have been efforts to standardize its protocols and to make it a valuable method for the characterization and diagnosis of patients with different types of occlusal conditions. ${ }^{12,13}$

Electromyographic studies suggest a higher electrical activity of the temporal muscle at rest and increased electrical activity of masseter in the mastication side preference. ${ }^{14}$ Other studies indicate that the masseter muscle contributes significantly to the generation of force during isometric contraction during dental tightening, whereas the temporal muscle is a positioner muscle that controls jaw movements. ${ }^{15,16}$ Other studies also indicate that the temporal muscle has higher activity than the masseter muscle, not only during dental tightening, but also during mastication. ${ }^{17}$

The disharmony of the neuromuscular system is considered one of many elements that cause not only muscle, but also joint diseases. Temporomandibular disorders (TMJ) involve multifactorial 
outstanding elements such as occlusion, along with the entire system, the psychological profile of the patient and stress levels, which play an important role that generates the appearance of various signs and symptoms, very common in the population of the region. ${ }^{18,19}$

One of the aforementioned signs is joint noise during mandibular biomechanics, which may represent a breakdown of the articular surfaces of the mandibular condyle and the articular disc. ${ }^{20}$ These findings have been corroborated by Jimenez-Quintana, ${ }^{21}$ who found that joint noise was the main sign during opening and closing movements. Other common problems in the population are functional disorders of the masticatory muscles, which mainly include pain and dysfunction as symptoms. Pain has being the most common symptom reported by patients who seek treatment, and who are characterized by an increased level of muscle activity caused by multiple psychosocial factors that increase the frequency and intensity of parafunctions controversially considered as a risk factor for developing TMJ. Bruxism, head, face and neck traumas, stress, anxiety, arthritis, very long appointments during dental treatments and neurological disorders are some factors that could cause TMJ.22

These two important clinical features, pain and/or joint noises were observed by Dos Santos, ${ }^{23}$ who relates occlusal factors as triggers of joint noises, especially in Class II malocclusions, whereas Cooper ${ }^{24}$ refers that pain symptoms are often accompanied by joint noise and edge wear of both upper and lower incisor. Joint noise as grinding noise may indicate any change in the TMD, because it is produced by an anachronistic and physiological relationship between the joint surfaces and meniscus in displacement system. ${ }^{25}$

There is wide literature that supports both physiological and pathological occlusal, joint and muscle conditions, but the epidemiological profile of our region is only clearly focused on dental caries, periodontal disease and craniofacial alterations. ${ }^{26,27}$ However, occlusal, joint and muscle conditions are not described, and the theoretical concept of occlusion is still based on theoretical framework built on ethnic populations, genetic, sociocultural, feeding, and parafunctional and postural conditions different from ours.

Thus, the aim of this study is to describe occlusal, temporomandibular joint and muscle characteristics of people aged between 18 and 27 years, with complete natural dentition. It used descriptive research design, and observed the following variables: symptomatic data refer to neuromuscular system or TMJ including or not the presence of parafunctional habits; description of opening and closing patterns, ranges of mandibular mobility, overbite, overjet, presence of joint noises, end feel, passive and active functional palpation of elevator and depressor muscles. In semi-adjustable articulators study the variables are static and dynamic occlusal characteristics, premature and interference contacts. It includes masseter and temporal electrical activity variable.

\section{Materials and methods}

The characterization of occlusal, joint and muscle conditions in young adult population between 18 and 27 years was conducted by a descriptive study. The sample consisted of 60 young adults aged between 18 and 27 , dentistry students at university who attended a diagnostic examination of the stomatognathic system. Dentate patients without prosthesis who accepted all required tests were included in the study. Patients with orthodontic apparatus or cold sore at the time of clinical examination were not included.
The study requested authorization from Bioethics Committee of the Autonoma University of Manizales (Minute 28-2013, June 19, 2013) to conduct the research. It complies with the standard Resolution 8430 of the Ministry of Health of Colombia, which governs health research. All participants were informed about the procedures and risks, and an informed consent was requested.Examiners were previously calibrated according to Kappa procedure (Kappa coincidence>0.6).

The data collection process included the following stages: Firstly, participants were asked about their symptomatic data that refer to neuromuscular system or TMJ including or not the presence of parafunctional habits.

Secondly, a clinical examination was conducted in a dental unit in daylight. Mouth mirrors, explorers and millimeter rulers were used to record measurements and clinical conditions of the patient taking into account all biosecurity standards.

The clinical examination included a description of opening and closing patterns, ranges of mandibular mobility (central and eccentric), overbite, overjet, passive and active probing of both temporomandibular joints, presence of joint noises, end feel, passive, active and functional palpation of elevator and depressor muscles, including head and neck muscles. Painful symptoms were also assessed in joints and muscles through pain visual analog scale by Serrano $^{28}$ as painless $=0$; mild pain $=1-2$; moderate pain $=3-5$; severe pain $=6-8$; unbearable pain $=9-10$.

After the clinical assessment, semi-adjustable articulators were mounted in centric relation position according to mounting protocols. ${ }^{29}$ Static and dynamic occlusal characteristics such as molar and canine classification, curves of Spee and Wilson, occlusal planes, canine guide, premature contacts and interference were analyzed to identify the most common occlusal patterns. The analysis of anterior teeth was supplemented with Kennedy models mounted in centric relation position.

Electromyography of masseter and temporal were made according to the protocol in Appendix 1 after analyzing centric mountings. This test provided information about the muscle, or referred to mastication, about the muscle groups in relation to contraction time and extent of its electrical activity. Some studies suggest than this test is an effective tool to quantify muscle activity during mastication, and therefore to identify functional changes. ${ }^{30}$

After completing the above procedures, the SPSS version 19 was used to analyze the information. Absolute and relative frequencies of occlusal, joint and muscle characteristics of the study population were assessed

\section{Results}

Clinical examination of both temporomandibular joints including assessment of neuromuscular mandibular elevators and depressors with occlusal analysis in semi-adjustable articulators and surface electromyography in 60 patients, 47 female and 13 male, with an average age of 21 was conducted. Seventy-three percent of the patients reported to have orthodontic treatments and $50 \%$ of them reported some type of joint noise, $21.7 \%$ expressed parafunctional habits of bruxism, and $11.7 \%$ reported pain in any of the masticatory muscles. It is important to highlight that during the anamnesis $48.3 \%$ of patients considered themselves under different stress factors. 
Clinical examination (Table 1) shows the range of normal opening in $68.3 \%$ of the sample, taking into account that $95 \%$ of patients showed soft end-feel. Conversely, some changes in the opening pattern were observed in $86.6 \%$ and there was clear predominance of mandibular deviations especially to the right side, and only $16,7 \%$ showed opening pattern without deviation, which is a sign of normal mandibular movements. A decrease in the ranges of motion in eccentric movements was also observed and relevant values of $56,7 \%$ were shown on the right side and $53.3 \%$ on left side.

Table I General Analysis of the temporo-mandibular joint variables

\begin{tabular}{|c|c|c|c|}
\hline & Categories & $\mathbf{n}$ & $\%$ \\
\hline Overbite in $\mathrm{mm}$ & $\begin{array}{l}\text { Less than } 3 \\
\text { Equal to } 3 \\
\text { Greater than } 3\end{array}$ & $\begin{array}{l}30 \\
15 \\
15\end{array}$ & $\begin{array}{l}50.0 \\
25.0 \\
25.0\end{array}$ \\
\hline Overjet in mm & $\begin{array}{l}1-2 \\
3 \\
4-5\end{array}$ & $\begin{array}{l}23 \\
26 \\
11\end{array}$ & $\begin{array}{l}38.3 \\
43.3 \\
18.3\end{array}$ \\
\hline Range of motion during right side in $\mathrm{mm}$ & $\begin{array}{l}3-6 \\
7-9 \\
10-12\end{array}$ & $\begin{array}{l}34 \\
25 \\
1\end{array}$ & $\begin{array}{l}56.7 \\
41.7 \\
1.7\end{array}$ \\
\hline Range of motion during left side in $\mathrm{mm}$ & $\begin{array}{l}3-6 \\
7-9 \\
10-12\end{array}$ & $\begin{array}{l}32 \\
26 \\
2\end{array}$ & $\begin{array}{l}53.3 \\
43.3 \\
3.3\end{array}$ \\
\hline Maximum opening in $\mathrm{mm}$ & $\begin{array}{l}29-40 \\
41-50 \\
51-59\end{array}$ & $\begin{array}{l}8 \\
41 \\
11\end{array}$ & $\begin{array}{l}13.3 \\
68.3 \\
18.3\end{array}$ \\
\hline Deviation & $\begin{array}{l}\text { No } \\
\text { Right } \\
\text { Left }\end{array}$ & $\begin{array}{l}10 \\
31 \\
19\end{array}$ & $\begin{array}{l}16.7 \\
51.7 \\
31.7\end{array}$ \\
\hline Deflection & $\begin{array}{l}\text { No } \\
\text { Right }\end{array}$ & $\begin{array}{l}58 \\
2\end{array}$ & $\begin{array}{l}96.7 \\
3.3\end{array}$ \\
\hline End- feel & $\begin{array}{l}\text { Hard } \\
\text { Soft }\end{array}$ & $\begin{array}{l}3 \\
57\end{array}$ & $\begin{array}{l}5.0 \\
95.0\end{array}$ \\
\hline Right side clicking & $\begin{array}{l}\text { Yes } \\
\text { No }\end{array}$ & $\begin{array}{l}17 \\
43\end{array}$ & $\begin{array}{l}29 \\
71\end{array}$ \\
\hline Left side clicking & $\begin{array}{l}\text { Yes } \\
\text { No }\end{array}$ & $\begin{array}{l}26 \\
34\end{array}$ & $\begin{array}{l}43.3 \\
56.6\end{array}$ \\
\hline Right side jump & $\begin{array}{l}\text { Yes } \\
\text { No }\end{array}$ & $\begin{array}{l}6 \\
54\end{array}$ & $\begin{array}{l}10 \\
90\end{array}$ \\
\hline Left side jump & $\begin{array}{l}\text { Yes } \\
\text { No }\end{array}$ & $\begin{array}{l}16 \\
44\end{array}$ & $\begin{array}{l}26.6 \\
73.3\end{array}$ \\
\hline Temporalis muscle pain & $\begin{array}{l}\text { Yes } \\
\text { No }\end{array}$ & $\begin{array}{l}3 \\
57\end{array}$ & $\begin{array}{l}5 \\
95\end{array}$ \\
\hline Masseter muscle pain & $\begin{array}{l}\text { Yes } \\
\text { No }\end{array}$ & $\begin{array}{l}4 \\
56\end{array}$ & $\begin{array}{l}6.7 \\
93.3\end{array}$ \\
\hline Trapezius muscle pain & $\begin{array}{l}\text { Yes } \\
\text { No }\end{array}$ & $\begin{array}{l}2 \\
58\end{array}$ & $\begin{array}{l}3.3 \\
96.7\end{array}$ \\
\hline Sternocleidomastoid muscle pain & $\begin{array}{l}\text { Yes } \\
\text { No }\end{array}$ & $\begin{array}{l}3 \\
57\end{array}$ & $\begin{array}{l}1 \\
99\end{array}$ \\
\hline Tempro-mandibular joint & $\begin{array}{l}\text { Yes } \\
\text { No }\end{array}$ & $\begin{array}{l}0 \\
60\end{array}$ & $\begin{array}{l}0 \\
100\end{array}$ \\
\hline
\end{tabular}

Clinical evaluation revealed complete absence of pain in both joints, and low percentage of pain in some muscle group especially at temporalis (only 16.7\%), classified as mild according to the scale of Serrano. Moreover, joint auscultation showed the existence of joint noises, clicking noises present in $43.3 \%$ on the left side, and $28.3 \%$ on the right (Table 2).
Table 2 Static analysis of mounting models in semi-adjustable articulator

\begin{tabular}{|c|c|c|c|}
\hline Variables & Categories & $\mathbf{n}$ & $\%$ \\
\hline \multirow[t]{3}{*}{$\begin{array}{l}\text { Occlusal plane in the articulator } \\
\text { right side of the patient }\end{array}$} & Straight & 55 & 91.6 \\
\hline & Stepped & 4 & 6.7 \\
\hline & Irregular & 1 & 1.7 \\
\hline \multirow[t]{3}{*}{$\begin{array}{l}\text { Occlusal plane in the articulator left } \\
\text { side of the patient }\end{array}$} & Straight & 54 & 90 \\
\hline & Stepped & 5 & 8.3 \\
\hline & Irregular & I & 1.7 \\
\hline \multirow[t]{2}{*}{$\begin{array}{l}\text { Curve of Spee in articulator right } \\
\text { side }\end{array}$} & Concave & 56 & 93.3 \\
\hline & Convex & 4 & 6.7 \\
\hline \multirow[t]{2}{*}{$\begin{array}{l}\text { Curve of Spee in articulator left } \\
\text { side }\end{array}$} & Concave & 59 & 98.3 \\
\hline & Stepped & 1 & 0I-Jul \\
\hline \multirow[t]{2}{*}{ Curve of Wilson in the articulator } & Concave & 58 & 96.7 \\
\hline & Convex & 2 & 3.3 \\
\hline \multirow[t]{4}{*}{ Classification of right molars } & Class I & 44 & 73.3 \\
\hline & Class II & II & 18.3 \\
\hline & Class III & I & 1.7 \\
\hline & Not applicable & 4 & 6.7 \\
\hline \multirow[t]{4}{*}{ Clasificación of left molars } & Class I & 34 & 56.7 \\
\hline & Class II & 19 & 31.7 \\
\hline & Class III & 2 & 3.3 \\
\hline & Not applicable & 5 & 08-Mar \\
\hline \multirow[t]{3}{*}{ Canine classification of right side } & Class I & 43 & 71.7 \\
\hline & Class II. & 16 & 26.7 \\
\hline & Class III & I & 1.7 \\
\hline \multirow[t]{2}{*}{ Canine classification of left side } & milk, & 41 & 68.3 \\
\hline & Class III. & 19 & 31.7 \\
\hline
\end{tabular}

An occlusal analysis after clinical examination on articulated models showed, as one of the most relevant findings, higher proportion of occlusal characteristics associated with normal occlusion with an outstanding presence of overbite between 1 and $2 \mathrm{~mm}$ in $51.6 \%$. Likewise, overjet was between 1 and $3 \mathrm{~mm}$ (normal range) was present in $55 \%$ of the population. between 1 and $2 \mathrm{~mm}$ in $51.6 \%$. Likewise, overjet was between 1 and $3 \mathrm{~mm}$ (normal range) was present in 55\% of the population.

In the occlusal plane, compensation curves of Spee and Wilson showed prevalence of signs considered normal occlusion. Class I within molar and canine classification was found in high percentage and it was more common on the right side $(71.7 \%$ canine Class I on right side and $68.3 \%$, canine Class I on left side). It is important to emphasize that the presence of canine and molar relationships Class II was higher than Class III, which had a percentage lower than $2 \%$ bilaterally (Table 2).

Unlike static analysis, dynamic analysis revealed the presence of 
occlusal elements that are not compatible with the normal parameters of occlusion, among which premature contacts were identified in $80 \%$ of the mountings with a predominant location in right premolars $(63.5 \%)$.

Likewise, the most common pattern of desocclusion was canine guidance in $76.7 \%$, however, it was possible to identify interference in both working and balancing side for various excursive movements, a feature that is not compatible with dynamic normal occlusion. In terms of laterality interference in working movement, the highest proportion was in molar on the right side (35\%), while in the balance side only $23.3 \%$ of the cases was identified on the right side of premolars, and on the left side they did not exceed $6.7 \%$.

At the same time, it is important to emphasize that in conducting the analysis of a model of Kennedy, an anterior teeth coupling without interference of the posterior teeth was found in a little more than half of the cases of evaluated patients (56.7\%). However, the presence of posterior occlusion reduced the percentage of anterior coupling to half (Table 3).

The electromyographic analysis showed that muscle activity is not homogeneous for each muscle group; some muscle groups Table 3 Dynamic analysis of mounting models in semi-adjustable articulator increased their electrical activity in different clinical conditions. The data took into account the maximum voluntary contraction and electrical activity during the masticatory process, which determined characteristics of muscle activity clinically observed in masseter and temporalis muscles. According to these findings, it was determined that the average sign muscle activity was much higher in temporal muscles than in masseters

Occlusion conditions specially those incompatible with normal eccentric movements affected the increase of electrical activity of masseter and temporalis muscles. The premature contacts in the exploration of joint models reflected higher muscular electrical activity compared with those that did not have such contacts. Also, when patients with premature contact to the maximum intercuspation were asked to chew showed and kept higher electrical activity of the right masseter and left temporalis muscles. There was statistical difference of electrical activity in MVC of Right masseter and left Temporalis muscle between patients with premature contacts and without it (Table 4) In maximum voluntary contraction and mastication in the lateral movement toward either side, there was no statistical difference between patients with and without lateral interference in balance and work (Table 5).

\begin{tabular}{|c|c|c|c|c|}
\hline \multirow[t]{2}{*}{ Categories } & \multicolumn{2}{|c|}{ Yes } & \multicolumn{2}{|c|}{ No } \\
\hline & $\mathrm{n}$ & $\%$ & $\mathrm{n}$ & $\%$ \\
\hline Premature contact & 48 & 80 & 12 & 20 \\
\hline Canine guidance & 46 & 76.7 & 14 & 23.3 \\
\hline $\begin{array}{l}\text { Interference in the right lateral side of } \\
\text { work }\end{array}$ & 21 & 35 & 39 & 65 \\
\hline Interference in the left lateral side of work & 19 & 31.7 & 41 & 68.3 \\
\hline $\begin{array}{l}\text { Interference in the right lateral side of the } \\
\text { balance }\end{array}$ & 14 & 23.3 & 46 & 76.7 \\
\hline $\begin{array}{l}\text { Interference in the left lateral side of the } \\
\text { balance }\end{array}$ & 4 & 6.7 & 56 & 93.3 \\
\hline Anterior coupling in articulated models & 30 & 5 & 30 & 5 \\
\hline Anterior coupling Kennedy classification & 34 & 56.7 & 26 & 43.3 \\
\hline
\end{tabular}

Table 4 Analysis of maximum voluntary contraction in masseter and temporalis muscles by the presence of premature contacts

\begin{tabular}{|c|c|c|c|c|c|}
\hline \multirow[b]{2}{*}{ Muscle Amplitud sEMG $(\mu \mathrm{V})$} & \multicolumn{2}{|c|}{ Presence of premature contacts } & \multicolumn{2}{|c|}{ No premature contacts } & \multirow[t]{2}{*}{ Statistical difference* } \\
\hline & Mean & SD & Mean & SD & \\
\hline MVC Right masseter & 739.8 & 202.2 & 619.2 & 209.7 & $155,5(0,035)^{* *}$ \\
\hline MVC Left masseter & 725.8 & 204.3 & 605.6 & 292.2 & I $75(0,083)$ \\
\hline MVC Right Temporalis muscle & 780.4 & 131.2 & 740.1 & 233.0 & $202,5(0,23 \mathrm{I})$ \\
\hline MVC Left temporalis muscle & 780.6 & 148.6 & 745.7 & 221.8 & $202,5(0,23 I)$ \\
\hline Mastication Right masseter & 183.0 & 42.2 & 162.3 & 26.2 & $256,5(0,884)$ \\
\hline Mastication left masseter & 172.8 & 32.5 & 159.5 & 28.4 & $228,5(0,489)$ \\
\hline Mastication Right Temporalis muscle & 189.6 & 40.4 & 182.5 & 41.1 & $260(0,938)$ \\
\hline Mastication Left temporalis muscle & 194.2 & 38.0 & 165.8 & 27.6 & $136(0,0 \mid 3)^{* * *}$ \\
\hline
\end{tabular}

*Statistical tests performed with $\left({ }^{b}\right)$ mann-whitney $U$ for couples of groups.

**Statistically significant

MVC, maximum voluntary contraction 
Table 5 Statistical comparison of sEMG amplitudes of the masticatory muscles studied between patients with and without lateral interference in balance and work

\begin{tabular}{|c|c|c|c|c|}
\hline & $\begin{array}{l}\text { Lateral Inter ference working } \\
\text { Right side interference }\end{array}$ & $\begin{array}{l}\text { Working left side } \\
\text { interference }\end{array}$ & $\begin{array}{l}\text { Balance right side } \\
\text { interference }\end{array}$ & $\begin{array}{l}\text { Balance left side } \\
\text { interference }\end{array}$ \\
\hline \multicolumn{5}{|c|}{ Muscle amplitud sEMG $(\mu \mathrm{V})$} \\
\hline $\begin{array}{l}\text { CVM masetero } \\
\text { Derecho }\end{array}$ & $386(0,837)$ & $311(0,263)$ & $312,5(0,964)$ & $57(0,11)$ \\
\hline $\begin{array}{l}\text { Mastication Right } \\
\text { Masseter }\end{array}$ & $369,5(0,64)$ & $282,5(0,114)$ & $255,5(0,289)$ & $105(0,88)$ \\
\hline CVM left masseter & $308(0,15)$ & $336(0,475)$ & $304,5(0,852)$ & $59(0,124)$ \\
\hline $\begin{array}{l}\text { Mastication left } \\
\text { masseter }\end{array}$ & $364,5(0,585)$ & $366,5(0,827)$ & $295,5(0,728)$ & $108(0,952)$ \\
\hline $\begin{array}{l}\text { CVM Right } \\
\text { temporal }\end{array}$ & $280,5(0,06 I)$ & $355,5(0,691)$ & $297,5(0,755)$ & $68(0,205)$ \\
\hline $\begin{array}{l}\text { Mastication Right } \\
\text { temporal }\end{array}$ & $347(0,4 I)$ & $3 \mid 4,5(0,288)$ & $24 \mid(0,187)$ & $77(0,32)$ \\
\hline $\begin{array}{l}\text { CVM Left } \\
\text { temporal }\end{array}$ & $335,5(0,315)$ & $360,5(0,752)$ & $308,5(0,908)$ & $100(0,763)$ \\
\hline $\begin{array}{l}\text { Mastication Left } \\
\text { Temporal }\end{array}$ & $318,5(0,202)$ & $335,5(0,47)$ & $280,5(0,539)$ & $99(0,74)$ \\
\hline
\end{tabular}

*Statistical tests performed with $\left({ }^{b}\right)$ mann-whitney $U$ for couples of groups.

**Statistically significant

MVC, maximum voluntary contraction

\section{Discussion}

This study assessed 60 young adult patients, 47 female and 13 males, 21 years average age. The study aimed to characterize the muscle and joint function in a population through clinical examination and electromyography.

The results showed different clinical and occlusal conditions with no muscle or joint pain, joint mobility with some limitations in eccentric movements, straight occlusal planes, concave curves of Spee and Wilson; static occlusal patterns with malocclusion, including bilateral molars and canine Class I. It is important to note that $73 \%$ of participants reported a record of orthodontic treatment; but there were also signs compatible with any pathological condition as joint noises, changes in the opening pattern, premature contacts mainly in upper premolars and occlusal working and balancing interferences that increase the demand of periodontal mechanoreceptive, and also increase neuromuscular complex activity involving different mandibular elevator muscles.

Nowadays the concept of occlusion is not only focused on interact tooth relationships, on the contrary, it is considered a complex of muscles, ligaments, joints and teeth relationship that can be influenced by some variables such as gender, age, stress factors and any other element that increases neuromuscular activity. ${ }^{31}$ Temporomandibular disorders include clinical signs related to the TMJ, the limitation of mandibular movements, presence of joint noises, headache, earache, occlusal trauma are some signs among others. The etiology of these pathologies has been reported by many factors, it can be influenced by traumatic or degenerative injuries, musculoskeletal problems, malocclusion, parafunctional habits and psychosocial factors. ${ }^{32,33}$ Some of these signs were found in the presence of clicking joint noises (43.3\% of cases), especially on the left side, while the presence of jump joint is representatively lower with only $26.6 \%$. They mark the evaluated muscle activity in electromyographic recordings. It is important to note that the absence of pain symptoms in temporomandibular joint and very little pain, only $10 \%$ in muscle components. This sign can represent low levels of fatigue and muscle strain, which may impact on the little prevalence of muscle diseases. ${ }^{34}$

Occlusal conditions marked a tendency to normal occlusion patterns in the static analysis, but with undesirable contacts at dynamic level. Premature contacts, balancing and working interference have been linked to the difference between the position of centric relation and typical occlusion; they have been commonly identified as predisposing factors and causes of various temporomandibular disorders. ${ }^{35}$

The literature also reports controversy about the effect of interfering contacts on the neuromuscular component. Some studies suggest that mediotrusive contacts are perceived by neuromuscular system differently than other types of occlusal contacts. It shows that all dental contacts are of inhibitory nature, which means that their presence reduces muscle activity due to the nociceptors and proprioceptors of the PDL that, under proper stimulation, cause inhibition responses. ${ }^{36}$ However, other electromyographic studies suggest that the presence of mediotrusive contacts in posterior teeth increases muscle activity. It agrees with the results of the study because the premature contacts observed in the right upper premolars increased electrical muscle activity especially in the right temporal muscle. Although, this fact can be demonstrated, its rationale is still unclear. ${ }^{37}$ Statistically significant difference between the electrical activity of the right masseter and left temporalis, when comparing patients with and without premature contact was found, this explains 
that premature contacts generate an occlusal instability that is offset by a change in the mandibular position, which affects neuromuscular component.

Williamson and Lundquist. ${ }^{38}$ assessed the effect of different patterns of occlusal contact in temporal and masseter muscles and they observed that when mediotrusive contacts are removed, only working muscles were active. That study also showed that if there is a group function, the masseter and temporal working side are active during laterotrusive movement. However, if only the canines contact during this movement (canine guide), only the temporalis muscle is active during the same movement. Thus, benefits of canine guidance respect to the role of group and mediotrusive, this fact corresponds to this study results. However, it cannot be stated that electrical muscle activity reduces because of canine guidance since this feature was not taken into account in the electromyography, but it is important to note that the study population revealed a high percentage $(76.7 \%)$ of the desocclusive pattern.

The alterations of centric or eccentric occlusal contacts can affect the electromyographic activity of the masticatory muscles. Bakke ${ }^{39}$ artificially generated premature contact, which determined higher electromyographic activity during maximum voluntary contraction due to an asymmetrical contraction of all muscles, and it was higher in ipsilateral side contact. Michelotti ${ }^{36}$ found no significant differences in EMG activity in masseter with interference. The author states that healthy individuals have better to be adapted to occlusal changes than individuals with temporomandibular disorders.

Rilo $^{40}$ observed the average muscle activity of signals and found higher values in temporal muscles compared to the masseter. This condition is consistent with the study in which temporal pattern increased muscle electrical activity and this can favor the occurrence of any pathology. Most of the authors agree that temporalis muscle is the most active muscle in dental occlusion, higher than that of the masseter muscle and as muscular effort increases, the activity of masseter and overcome temporalis muscle increases. ${ }^{41,42}$

Rosemberg ${ }^{43}$ stated that interarch relationships are key to balance the functions of the masticatory system. In that study, five key aspects were reported, interarch and intraarch integrity, which occurs thanks to right tooth positioning, is especially important. There should not be occlusal alterations and mandibular biomechanic balance and stability should be ensured to increase the efficiency of the masticatory process. Likewise, there should be an Angle Class I molar relationship, an inter-occlusal available space with adequate overbite and overjet, which allow proper mandibular functional movements. These conditions agree with the study findings where Class I molar relationship and adequate anterior guidance prevailed.

It is important to remark that the participants are young adults with higher prevalence of occlusal characteristics of normal orthodontic record $(73 \%)$. Although the occlusal plane found in most cases is normal, there were premature contacts and interferences, and clinical findings that cause dental instability that increased occlusal forces, it produces type I or type II levers and a remarkable increase in the masticatory muscle activity.

\section{Conclusion}

i. The clinical examination revealed clinical signs of normality in presence of pathognomonic signs as joint noise and joint jumps prevail on the left side. These are associated with mandibular deviations alterations as main sings of opening pattern.

ii. The static analysis of joint models showed predominance of occlusal patterns with normal occlusion. However, the dynamic analysis revealed the presence of premature contacts, interference in excursive movements and prevalence of canine desocclusion.

iii. The EMG analysis showed increase of electrical activity in temporal and masseter muscles in the presence of noise, jumps, and changes in opening pattern premature contacts, occlusal interferences and during the masticatory cycle the temporal muscles had the highest electromyographic values.

\section{Recommendation}

Population baselines should be considered for future studies to diagnose joint and muscle diseases, and to describe direct or indirect relationship of the occlusal factors with them and at the same time to build epidemic profiles of the population of the region.

\section{Acknowledgments}

The authors thank Universidad Autónoma de Manizales (Colombia) for financing this work and to Diana E. Abril B , Alexandra Suaza R and Thomas Owen Lock Translators of the Translation Center of the Autonoma University of Manizales-UAM.

\section{Conflicts of interest}

The authors declare no conflicts of interest.

\section{References}

1. Díaz GS, Hidalgo HS, Gómez MM, et al. Dental occlusion. reflections more than conjectures. In Camagüey: AMC. 2008.

2. Aúcar LJ, López CR, Díaz GS, et al. Behavior of chewing patterns and craniomandibular dysfunction in adults with an absent molar. Archivo Médico de Camagüey. 2007.

3. Molerio PD. Current stress. villa clara: Universidad control, Martha Abreu. 2004.

4. Espinosa MJ, Iba SDG, Álvarez AA. Bruxismo. Jano EML. 2003; 55(1268):51-56.

5. Zielinsky L. Methodology for the cephalometric analysis as a basis for staggered decisions. Rev Cubana Ortod. 1995;10(1):29.

6. McNeill C. Current controversies in temporomandibular disorders. Chicago: Quintessence Publishing co. 1992.

7. Pullinnger A, Seligman D, Solberg W. Temporomandibular disroders Part II: Occlusal factors associated with temporomandibular joint tenderness and dysfunction. Journal of Prosthetic Dentistry. 1988;59(3):363-367.

8. Magnusson T, Enbom L. Signs and symptomas of mandibular dysfuntion after introduction of experimental balancing side interferences. Acta Odontol Acand. 1984;42(3):129-135.

9. Andrews LF. The six keys to normal occlusion. Am J Orthod. 1972;62:296309.

10. Okeson J. Treatment of occlusion and temporomandibular conditions. Quinta ed: Mosby; 2003.

11. Farina D, Merletti R, Enoka R. The extraction of neural strategies from the surface EMG. J Appl Physiol. 2004;96(4):1486-1495. 
12. Hannam A, Wood W. Relationships between the size and spatial morphology of human masseter and medial pterygoid muscles, the craniofacial skeleton, and jaw biomechanics. Am J Phys Anthropol. 1989;80(4):429-445.

13. Sassi F, Andrade C. Surface electromyography and the treatment of stuttering: a neuromotor perspective. Rev Soc Bras Fonoaudiol. 2004;9(1):55-60.

14. Felício C, Sidequersky F, Tartaglia G, et al. Electromyographic standardized indices in healthy Brazilian young adults and data reproducibility. J Oral Rehabil. 2009;36(8):577-583.

15. McCarroll R, Naeije M, Hansson T. Balance in masticatory muscle activity during natural chewing and submaximum clenching. J Oral Rehabil. 1989;16(5):441-446.

16. Kerstein R. Combining technologies: a computerized occlusal analysis system synchronized with a computerized electromyography system. Cranio. 2004;22(2):96-109.

17. Moreno I, Sanchez T, Ardizone I, et al. Electromyographic comparisons between clenching, swallowing and chewing in muscle with varying occlusal parameters. Med Oral Patol Oral Cir Bucal. 2008;13(3):E207213

18. Glatos A, Glass E, McLaughiin L. Knowledge and beliefs of dentists regarding tiemporomandibular disorders and chronic pain. J Orofacial Pain. 1994;8:216-222.

19. Nekora-Azak A, Evlioglu G, Ordullu M, et al. Prevalence of Symptoms associated with temporomandibular disorders in a Turkish population. $J$ Oral Rehabil. 2006;33(2):81-84.

20. Buescher J. Temporomandibular joint disorders. Clarkson Family Medicine. 2007;76(10):1477-1482.

21. Jiménez-Quintana Z, De los Santos Solana L, Sáez Carriera R, et al. Prevalencia de los trastornos temporomandibulares en la población de 15 años y más de la Ciudad de La Habana. Rev Cubana Estomatol. 2007;44(3).

22. Aditya A, Lele S, Aditya P. Prevalence of symptoms associated with temporomandibular disorders in patients with psychosocial disorders. Journal of International Dental and Medical Research. 2012;5(1):26-29.

23. Dos Santos J. The prevalence of TMJ cliking and its relationship to dental occlusion type in a group of young Mexicans. Revista ADM. 2011;68(5):237-243.

24. Cooper B, Kleinberg I. Examination of a large patient population for the presence of symptoms and signs of temporomandibular disorders. Cranio. 2007;25(2):114-126.

25. Martínez R. Oclusión orgánica. México.: Salvat mexicana de edicione S.A. de CV; 1995

26. Arrieta Vergara K, Diaz Caballero A. Prevalence of caries and periodonta disease in students of stomatology. Revista Cubana de Estomatología. 2011;48(1):6-13.

27. Killiaridis S, Johansson A, Haraldson T, et al. Craniofacial morphology occlusal traits, and bite force in persons with advance occlusal tooth wear Am J Orthod Dentofacial Orthop. 1995;107(3):286-292.
28. Serrano Atero M, Caballero J, Cañas A. Valoración del dolor (I). Rev Soc Esp Dolor. 2002;9:94-108.

29. Alonso A, Albertini S, Bechelli H. Occlusion and diagnosis in oral rehabilitation: Medica Medica Panamericana; 2004.

30. Felício C, Sidequersky F, Tartaglia G, et al. Electromyographic standardized indices in healthy Brazilian young adults and data reproducibility. J Oral Rehabil. 2009;36(8):577-583.

31. DiazE, Coronel M. Prevalence of signs and symptoms of temporomandibular dysfunction according to the different malocclusions. 2007; 8:35-43.

32. Aditya A, Lele S, Aditya P. Prevalence of symptoms associated with temporomandibular disorders in patients with psychosocial disorders. Journal of International Dental and Medical Research. 2012;5(1):26-29.

33. Tenorio J. Signs and symptoms relevant to the presumptive clinical diagnosis of TMJ alteration in a population of adults 50 years and older in Mexico city. National Autonomous University of Mexico. Mexico; 2006.

34. Lobbezoo F. Topical review: new insights into the pathology and diagnosis of disorders of the temporomandibular joint. J Orofac Pain. 2004;18(3):181-191

35. Magnusson T, Enbom L. Signs and symptomas of mandibular dysfuntion after introduction of experimental balancing side interferences. Acta Odontol Acand. 1984;42(3):129-135.

36. Michelotti A, Farella M, Gallo LM, et al Effect of occlusal interference on habitual activity of human masseter. J Dent Res. 2005;84:644-648.

37. Bakke M, Holm B, Jensen B, et al. Unilateral, isometric bite force in 8-68-year-old women and men related to occlusal factors. Scand J Dent Res. 1990;98:149-158.

38. Williamson EH, Lundquist DO. Anterior Guidance: its effect on electromyographic activity of the temporal and masseter muscles. $J$ Prosthet Dent. 1983;49(6):816-23.

39. Bakke M, Holm B, Jensen B, et al. Unilateral, isometric bite force in 8-68-year-old women and men related to occlusal factors. Scand J Dent Res. 1990;98:149-158

40. Rilo B, Santana V, Mora M, et al. Myoelectrical activity of clinical rest position and jaw muscle in Young adults. J Oral Rehabil. 1997;24(10):735740 .

41. Throckmorton G, Dean J. The relationship between jaw -muscle mechanical advantage and activity levels during isometric bites in humans. Archs Oral Biol. 1994;39:429-437.

42. Naeije M, McCarroll R, Weijs W. Electromyographic activity of the human masticator muscles during sub maximum clenching in the intercuspal position. J Oral Rehabil. 1989;16:63-70.

43. Rosemberg. Treatament of occlusion as an adjunct to periodontal therapy. Soc periodontal. 1967;1:14. 